\title{
Residual Cancer Burden Class 1
}

National Cancer Institute

\section{Source}

National Cancer Institute. Residual Cancer Burden Class 1. NCI Thesaurus. Code C160726.

Minimal residual disease; low chance of disease recurrence. 